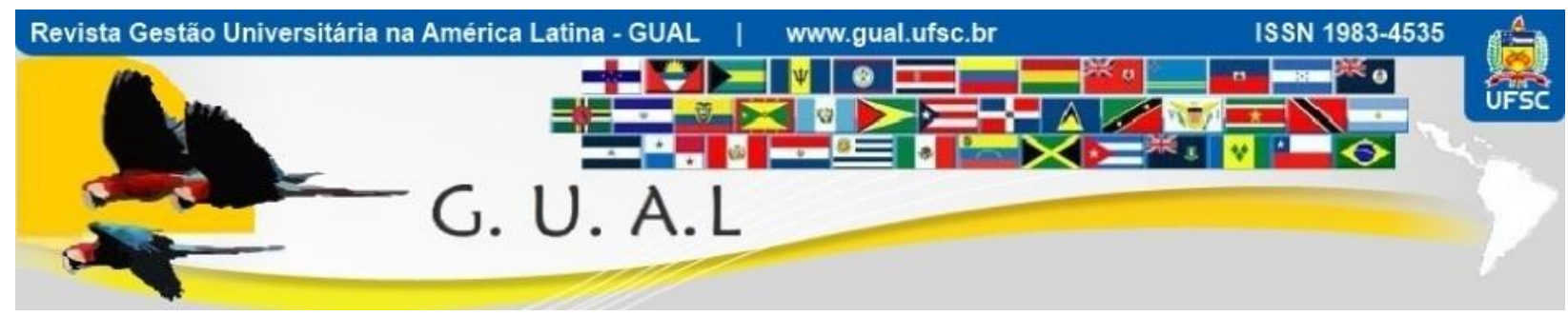

DOI: http://dx.doi.org/10.5007/1983-4535.2014v7n3p160

\title{
ADMINISTRAÇÃO UNIVERSITÁRIA: DESVENDANDO O CAMPO CIENTÍFICO NO BRASIL
}

\section{UNIVERSITY ADMINISTRATION: UNRAVELING THE SCIENTIFIC FIELD IN BRAZIL}

Raphael Schlickmann, Doutor

UDESC/UNISOCIESC

raphas82@gmail.com

Maurício Roque Serva de Oliveira, Doutor Universidade Federal de Santa Catarina - UFSC

mauserva@gmail.com

Pedro Antônio de Melo, Doutor Universidade Federal de Santa Catarina - UFSC pedro.inpeau@gmail.com

Recebido em 15/maio/2013

Aprovado em 03/fevereiro/2014

Sistema de Avaliação: Double Blind Review

Esta obra está sob uma Licença Creative Commons Atribuição-Uso. 


\title{
RESUMO
}

Ao se perceber que a administração universitária no Brasil, pode ser vista como um subcampo científico da administração no país, e tomando por base a abordagem sobre o campo científico de Bourdieu (1983; 2004), o objetivo central deste trabalho é o de analisar como está constituída a administração universitária enquanto campo científico no Brasil. Como resultados principais pode-se apontar: a identificação de 233 agentes-pesquisadores, 17 grupos de pesquisa e 18 cursos de pós-graduação stricto sensu em administração atuando no campo científico da administração universitária no Brasil, conforme os critérios utilizados. Verificou-se que existe a presença de temas que não necessariamente estejam relacionados à administração, mas ao ensino ou a educação superior. Quanto à estrutura do campo foi identificada uma relativa desigualdade na distribuição de capital científico, independente do tipo (puro ou institucional) considerado. Constatou-se que existe maior facilidade em se obter poder científico que prestígio acadêmico neste campo. Ainda, concluiu-se que os agentes tendem a atuar em locais mais próximos aos dominantes para ocupar melhores posições no campo. As fontes de capital científico mais importantes para ocupar posições de destaque no campo estão ligadas principalmente à titulação e à experiência profissional dos agentes.

Palavras-chave: Administração universitária. Campo científico. Capital científico.

\begin{abstract}
When you realize that the university administration in Brazil, can be seen as a scientific subdiscipline of administration in the country, and based on the scientific approach to the field of Bourdieu $(1983,2004)$, the central aim of this paper is to analyze how the university administration is constituted as a scientific field in Brazil. The main results of this study may point: the identification of 233 agents - researchers, 17 research groups and 18 courses of post- graduate studies in management acting in the scientific field of university administration in Brazil, according to the criteria used . It was found that there is the presence of themes that are not necessarily related to the administration, but to education or higher education. Regarding the structure of the field it was noted that there is a relative inequality in this distribution independent of the type of scientific capital (pure or institutional ) considered. It was found that there is greater ease in obtaining scientific power that academic prestige in this field. Still, it was concluded that agents tend to operate in locations closer to the dominant to occupy top positions in the field. The most important sources of scientific capital to occupy prominent positions in the field are mainly related to the degree and professional experience of the agents.
\end{abstract}

Keywords: University administration. Scientific field. Scientific capital. 


\section{INTRODUÇÃO}

O campo científico, concebido como uma estrutura em que agentes ocupam posições a partir do acúmulo de capital científico por meio de lutas (BOURDIEU, 1983), torna-se uma das categorias de análise que viabilizam o estudo da atividade dos cientistas enquanto atores sociais, cooperando ou rivalizando segundo modalidades particulares em instituições específicas (BOUDON, 1990). Considerando a administração universitária no Brasil como um subcampo científico da administração, e tomando por base a abordagem de Bourdieu (1983; 2004) concernente ao tema, o objetivo central deste trabalho é o de analisar como está constituída a administração universitária enquanto campo científico no país. Para alcançar esse objetivo, buscou-se mais especificamente identificar e caracterizar os agentes do campo em questão; verificar possíveis influências das teorias administrativas nos temas de interesse do campo científico da administração universitária; e determinar a estrutura desse campo a partir do volume de capital científico puro e institucional acumulado por seus agentes.

Nesse sentido, estruturou-se o presente artigo em quatro partes. Na primeira parte são apresentados os pressupostos teóricos que embasaram esta pesquisa: o conceito de campo científico de Bourdieu foi desenvolvido como categoria de análise no âmbito da sociologia da ciência. Na segunda parte é apresentada a metodologia da pesquisa, com a definição das categorias de análise e os procedimentos de coleta e análise de dados. Na terceira parte são reportados os principais resultados da pesquisa, e em seguida algumas considerações finais e recomendações para trabalhos futuros.

\section{CAMPO CIENTÍFICO EM BOURDIEU}

É com base na ideia do espaço científico como um sistema de trocas que Pierre Bourdieu vai desenvolver seus estudos de sociologia da ciência. Porém, ao contrário de autores como Merton (1979) e Hagstrom (1979), Bourdieu (1983) utiliza o conceito de campo científico em substituição ao de comunidade científica, empregada por aqueles (ÁVILA, 1997). Bourdieu em Os usos sociais da ciência: por uma sociologia clínica do campo científico, conferência e debate organizados pelo grupo francês Sciences en Questions do Instituto Nacional de Pesquisa Agronômica de Paris - INRA, em 1997 retoma $^{1}$ de forma bastante esclarecedora o conceito de campo científico.

\footnotetext{
${ }^{1} \mathrm{Na}$ década de 1970, nos artigos A especificidade do campo científico e as condições sociais do progresso da razão e $O$ campo científico trouxe pela primeira vez esses conceitos (BOURDIEU, 2004).
} 
Considerado como um "mundo social" específico, o campo científico é um campo de forças e, ao mesmo tempo, um campo de lutas para alterar ou transformar esse campo (BOURDIEU, 2004). Essas lutas se dão entre os agentes, os quais criam os espaços para essas lutas por meios das relações objetivas que estabelecem entre si (BOURDIEU, 2004). A estrutura das relações objetivas entre os diferentes agentes se constituem nos princípios do campo científico, determinando o que os agentes podem ou não fazer. Ou em outros termos, é a posição que os agentes ocupam nessa estrutura que determina suas tomadas de posição (BOURDIEU, 2004). Neste sentido, o campo científico pode ser entendido como um espaço em que agentes ou instituições ocupam uma posição adquirida em disputas históricas para obter a autoridade científica. A posição hierárquica obtida pelo agente no campo se dá, portanto, em função do quanto ele consegue impor sua autoridade científica, "espécie particular de capital social que assegura um poder sobre os mecanismos constitutivos do campo e que pode ser reconvertido em outras espécies de capital” (BOURDIEU, 1983, p. 127). Cabe destacar que como no campo econômico existe um tipo de capital específico (o capital econômico), no campo científico há também um tipo de capital específico, mais precisamente uma "espécie particular de capital simbólico (o qual é sempre fundado sobre atos de conhecimento e reconhecimento) que consiste no reconhecimento (ou no crédito) atribuído pelo conjunto de pares-concorrentes no interior do campo científico" (BOURDIEU, 2004, p. 26).

Bourdieu (2004) identifica duas espécies de capital científico — institucional e puro - correspondentes respectivamente a duas formas de poder: o poder temporal, também denominado político, institucional e institucionalizado e o poder específico. O poder temporal está relacionado às posições ocupadas pelos agentes nas instituições científicas, direção de laboratórios ou departamentos, pertencimento a comissões, comitês de avaliação, bancas de concursos, entre outras, além do "poder sobre os meios de produção (contratos, créditos, postos, etc.) e de reprodução (poder de nomear e de fazer carreiras) que ela assegura" (BOURDIEU, 2004, p. 35). O poder específico está ligado a um prestígio pessoal do agente que é relativamente independente do poder temporal, e que está baseado quase que exclusivamente sobre o reconhecimento do conjunto de pares ou de uma "fração consagrada dentre eles" (BOURDIEU, 2004, P. 35). Esta forma de poder dá origem a uma espécie de capital científico que está ligada ao reconhecimento pelos pares, é pouco institucionalizada e encontra-se aberta à contestação (SHINN; RAGOUET, 2008). Para cada espécie de capital científico existem leis de acumulação próprias. No caso do capital científico 
institucionalizado, o acúmulo se dá por meio de estratégias políticas e institucionais, como por exemplo, as participações em comissões; em bancas de dissertações, teses e concursos; em eventos científicos, em cerimônias, em reuniões, etc. Em relação ao capital científico puro, sua acumulação se dá, principalmente, pelas “contribuições reconhecidas ao progresso da ciência, as invenções ou as descobertas (as publicações, especialmente nos órgãos mais seletivos e mais prestigiosos, portanto aptos a conferir prestígio à moda de bancos de crédito simbólico, são o melhor indício)” (BOURDIEU, 2004, p. 36).

Subjacente a busca por este acúmulo de capital científico seja ele puro ou institucional, está uma luta entre os agentes do campo para impor uma definição de ciência que mais esteja de acordo com seus interesses específicos (BOURDIEU, 1983). A definição mais apropriada de ciência será “a que lhe permita ocupar legitimamente a posição dominante e a que assegure, aos talentos científicos de que ele é detentor a título pessoal ou institucional, a mais alta posição na hierarquia dos valores científicos” (BOURDIEU, 1983, p. 128).

O acúmulo de capital científico, resultante de lutas entre os agentes do campo, proporciona, assim, que o pesquisador ocupe uma posição na hierarquia do campo científico em que ele está inserido. Segundo Lahire (2002, p. 48) “a distribuição desigual do capital determina a estrutura do campo, que é, portanto, definida pelo estado de uma relação de força histórica entre as forças (agentes, instituições) em presença no campo". A hierarquia existente no campo faz com que os agentes sejam colocados em posições contrárias, dando espaço para aquilo que Bourdieu (1983) vai denominar de "luta científica". Nesta luta, os vencedores são aqueles que dominam o campo a ponto de "impor uma definição da ciência segundo a qual a realização mais perfeita consiste em ter, ser e fazer aquilo que eles têm, são e fazem" (BOURDIEU, 1983, p. 128). Assim, o que é considerado científico no campo é justamente o que determinam aqueles que dominam o campo. Vale lembrar o que diz Stengers (1990, p. 79-80) quando afirma que a questão da cientificidade é prática e designa sempre uma coletividade, pois "não é de um cientista, mas de uma coletividade que depende a resposta a essa questão" (isso é científico?).

Assim, um campo científico é formado por dois tipos de agentes. De um lado estão aqueles que querem manter seu status quo o que significa difundir suas concepções de ciência, e os meios para fazer a ciência, utilizando os aportes teóricos, metodologias e abordagens que julgam mais adequados, aos que Bourdieu (1983) define como dominantes. De outro, estão os dominados, aqueles que buscam um espaço no campo, também 
denominados de novatos, que podem utilizar duas estratégias distintas para entrada: a estratégia de sucessão e a estratégia de subversão.

O campo científico é, portanto, um espaço de lutas entre dominantes - aqueles que conseguem impor sua forma de fazer, pensar e agir cientificamente - e dominados - os agentes que lutam junto (por meio de estratégias de sucessão) ou contra (por meio de estratégias de subversão) na busca pelo acúmulo de capital científico.

\section{METODOLOGIA}

\subsection{DEFINIÇÃO CONSTITUTIVA DAS CATEGORIAS DE ANÁLISE}

A definição das categorias de análise tem por objetivo descrever de forma precisa como foram empregados os conceitos que guiaram a pesquisa. As categorias de análise foram definidas constitutivamente (VIEIRA, 2004) em função de auxiliarem no alcance dos objetivos de pesquisa, que por sua vez levaram a alcançar o objetivo deste trabalho. Assim, definiu-se como categorias de análise:

- Administração Universitária: disciplina ou campo científico que tem por objeto de estudo as organizações de educação superior e que conceitualmente pode ser definida como processo de planejar, organizar, liderar e controlar o trabalho dos membros das organizações de educação superior, e de usar todos os seus recursos disponíveis para atingir seus objetivos.

- Teorias Administrativas: são os trabalhos que "fazem parte de um pensamento pragmático, no sentido onde o que conta é o alcance dos resultados fixados como metas" (RUBEN, SERVA, CASTRO, 1995, p. 208), quais sejam aqueles que dizem respeito às teorias gerenciais (trabalhos que se orientam pela racionalidade com fins de rentabilidade, na trajetória iniciada por Taylor e Fayol) e às áreas funcionais (finanças, marketing, produção, recursos humanos, etc.). Além dos trabalhos que envolvem a teoria das organizações a qual "busca, sobretudo analisar, refletir e melhor compreender o espaço onde o trabalho é realizado embora não inteiramente despojado de um certo pragmatismo" (RUBEN, SERVA, CASTRO, 1995, p. 208).

- Agentes: são indivíduos ou instituições caracterizados pelo volume de capital científico e que determinam a estrutura do campo em proporção ao seu peso relativamente ao peso de todos os outros agentes, isto é, de todo o espaço científico (BOURDIEU, 2004, p. 24). 
- Capital científico: "espécie particular de capital simbólico (o qual é sempre fundado sobre atos de conhecimento e reconhecimento) que consiste no reconhecimento (ou no crédito) atribuído pelo conjunto de pares-concorrentes no interior do campo científico" (BOURDIEU, 2004, p. 26). Pode ser classificado em: puro quando o crédito é obtido em função do reconhecimento dos pares a sua contribuição ao progresso da ciência, tratando-se de um poder específico, de prestígio pessoal; ou institucional, em que o crédito é obtido a partir das posições ocupadas nas instituições científicas e do poder que detêm sobre os meios de produção e de reprodução que elas asseguram (BOURDIEU, 2004).

- Campo científico: o lugar, o espaço de jogo pela busca de autoridade científica no qual estão inseridos os agentes e as instituições que produzem, reproduzem ou difundem a ciência (BOURDIEU, 1983; 2004).

\subsection{DEFINIÇÃO OPERACIONAL DAS CATEGORIAS DE ANÁLISE}

A operacionalização das categorias de análise foi feita a partir de uma subdivisão em dimensões e indicadores ou temas correspondentes. A seguir é apresentado como cada uma das categorias de análise foi operacionalizada para esta pesquisa.

\subsubsection{Administração Universitária}

Antes de apresentar as dimensões em que a categoria "administração universitária" foi subdividida ressalta-se que para fins deste trabalho ela será utilizada como sinônima dos termos: "gestão universitária"; "gestão de instituições de ensino/educação superior"; "administração da educação superior"; "gestão da educação superior"; “administração do ensino superior"; e "gestão do ensino superior". Justifica-se tais associações ao uso recorrente destes em publicações na área. Feita esta observação, passa-se para a operacionalização desta categoria, a qual se optou por dividir em quatro dimensões e 37 temas:

- Teorias gerenciais: são os trabalhos orientados pela racionalidade com fins de rentabilidade, conforme a trajetória iniciada por Taylor e Fayol, mais especificamente referem-se às produções sobre administração universitária que envolvam as principais teorias relacionadas às funções desempenhadas pelo administrador e suas variações nas organizações, quais sejam: o planejamento, a organização, a direção e o controle.

- Áreas funcionais da administração: referem-se às produções sobre administração universitária que envolvam as áreas funcionais de uma organização (no caso deste 
estudo, a universidade e as instituições de educação superior). Optou-se por tomar como base as divisões acadêmicas estabelecidas atualmente pela Associação Nacional de Pós-Graduação e Pesquisa em Administração - ANPAD (2011), que tratam das áreas funcionais quais sejam: Administração da Informação, Administração Estratégica, Administração Financeira, Administração de Operações e Logística, Administração de Pessoas e Administração de Marketing.

- Teoria das organizações: referem-se aos trabalhos sobre administração universitária que envolvam alguns dos temas da divisão acadêmica de Estudos Organizacionais definidos pela ANPAD (2011b), quais sejam: Abordagem Institucional; Conhecimento, Aprendizagem e Inovação; Trabalho, Organização, Estado e Sociedade; Comunicação, Processos Discursivos e Produção dos Sentidos; Ontologia, Epistemologias, Teorias e Metodologias nos Estudos Organizacionais; Estudos Críticos e Práticas Transformadoras em Organizações; Gênero e Diversidade; Organizações Familiares; História e Memória em Organizações; Redes e Relacionamentos Intra e Interorganizacionais; e Simbolismos, Culturas e Identidades em Organizações.

- Temas específicos: denominou-se "temas específicos" aqueles que são recorrentes em publicações na área de administração universitária. Tomou-se por referência os temas que mais se repetiram ou que mais tiveram trabalhos apresentados no Colóquio Internacional sobre Gestão Universitária nas Américas ${ }^{2}$, um evento anual consolidado na área de administração universitária no Brasil e na América do Sul e que há 13 anos já contemplou a apresentação de mais de dois mil trabalhos sobre o tema, o que reflete a produção sobre administração universitária no Brasil. Além disso, considerou-se as disciplinas que fazem parte da estrutura curricular do Programa de Pós-Graduação em Administração Universitária da Universidade Federal de Santa Catarina - UFSC ${ }^{3}$, por ser o único na área de administração no Brasil com foco na administração universitária. Sendo assim, foram definidos os seguintes temas: Políticas da Educação Superior; Estrutura e funcionamento da Educação Superior; Universidade e Sociedade; Avaliação da Educação Superior; Educação a Distância; Universidade e Desenvolvimento Regional; Acesso, permanência e evasão; Ensino, pesquisa e

\footnotetext{
${ }^{2}$ Até o ano de 2011, o evento denominava-se Colóquio Internacional sobre Gestão Universitária na América do Sul.

${ }^{3}$ Único programa da área de Administração voltado para a Administração Universitária de acordo com a Coordenação de Aperfeiçoamento de Pessoal de Nível Superior - CAPES.
} 
extensão ${ }^{4}$; Estrutura acadêmica e administrativa; Internacionalização e mobilidade acadêmica; Universidade e Compromisso Social; Autonomia; e Cooperação Universidade-Empresa. Incluiu-se ainda, os temas "administração universitária" e suas variações, conforme já apresentado e os temas que têm as instituições de educação superior como objeto de estudo.

\subsubsection{Agentes}

Conforme Bourdieu (2004) os agentes podem ser tanto pessoas como grupos de pessoas. Sendo assim, dividiu-se os agentes em três categorias: pesquisadores, grupos de pesquisa e cursos de pós-graduação stricto sensu em administração. Para a operacionalização da categoria agentes-pesquisadores, fez-se uma subdivisão em duas dimensões que contemplaram 16 indicadores: Perfil Demográfico (sexo e local de atuação profissional); e Perfil Acadêmico (níveis de formação; locais de formação; áreas de formação; tempo de formação; áreas de atuação; linhas de pesquisa; temas de dissertações e teses; temas de projetos de pesquisa; temas de publicações em periódicos; temas de publicações em anais de eventos científicos; temas de livros e capítulos de livros; periódicos em que publicam; e eventos em que publicam). Para a operacionalização da categoria agentes-grupos de pesquisa, foi feita uma subdivisão em duas dimensões que contemplaram quatro indicadores, conforme descrito: Perfil Demográfico (local de funcionamento; instituição; e tempo de atuação) e Perfil acadêmico (temas de interesse). Para a operacionalização da categoria agentes-cursos de pós-graduação stricto sensu em administração, foi feita uma subdivisão em duas dimensões que contemplaram quatro indicadores: Perfil Demográfico (local de funcionamento; e instituição) e Perfil Acadêmico (conceito do curso; e temas de interesse).

\subsubsection{Capital Científico}

Em relação à operacionalização da categoria capital científico, foi feita uma subdivisão em duas dimensões, correspondendo às duas espécies de capital científico cunhadas por Bourdieu (2004): o capital científico puro e o institucional. Para o primeiro tipo foram estabelecidos 13 indicadores divididos em três grupos: titulação, experiência profissional e produção intelectual. Para o segundo tipo foram determinados oito indicadores

\footnotetext{
${ }^{4}$ Havia se considerado a hipótese de incluir uma temática que faz parte das divisões acadêmicas da ANPAD que têm relação com a administração universitária, qual seja "Ensino e Pesquisa em Administração", no entanto, optou-se por aglutinar as produções encontradas junto ao tema "Ensino, pesquisa e extensão".
} 
divididos em dois grupos: cargos ocupados e participação em bancas, conselhos, comissões e consultorias. Sobre tais indicadores é importante fazer algumas considerações. Bourdieu (2004) menciona algumas fontes de obtenção de capital científico, conforme mostrado no capítulo da fundamentação teórica, mas não chega a operacionalizá-los em indicadores como fez em Homo academicus, de 1984, com relação aos indicadores de capital universitário. Vale lembrar que neste estudo Bourdieu (2011) não analisa o campo científico apenas, mas o campo universitário francês, mais amplo, portanto, e que por consequência inclui outras espécies de capital simbólico não científicas. E mesmo os indicadores de capital científico puro e institucional utilizados são bastante específicos ao campo científico francês, como, por exemplo, a direção de um laboratório do Centro Nacional de Pesquisa Científica francês como uma fonte de prestígio científico. Por conseguinte, foi necessário fazer adaptações, bem como consultar outros trabalhos que trouxessem indicadores que permitissem refletir a realidade não do campo científico da administração, no qual a administração universitária é enquadrada como subcampo. Nesse sentido, foi preciso encontrar indicadores que pudessem legitimar aquilo que os agentes do campo científico da administração consideram relevantes a ponto de conferir a seus pares e a eles próprios prestígio ou poder.

Considerando o trabalho de Teixeira et al. (2012), os critérios utilizados pela CAPES na avaliação dos programas de pós-graduação em administração no último triênio 2007-2009, e os indicadores utilizados para análise dos currículos Lattes dos candidatos a ingressar na carreira docente em administração da UFRGS, foi possível viabilizar a determinação do volume de capital científico puro e institucional acumulado pelos agentes-pesquisadores do campo científico da administração universitária no Brasil. Optou-se por dividir os indicadores da dimensão capital científico puro, de acordo com divisão adotada pela UFRGS (UFRGS, $2011)^{5}$, para facilitar a adaptação das pontuações ${ }^{6}$ e pesos atribuídos a cada grupo de indicadores. Quanto aos grupos de indicadores do capital científico institucional, foi feita uma adaptação do trabalho de Teixeira et al. (2012), e incluídos os indicadores "Atuação como membro de corpo editorial" e "Atuação como revisor de periódico", os quais não estavam previstos por esses autores, mas tinham semelhança com indicadores adaptados de Bourdieu (2004; 2011).

Além dos indicadores, foi necessário criar uma pontuação de modo a dar pesos a cada um deles, pois nem todas as fontes de capital científico têm o mesmo grau de importância

\footnotetext{
${ }^{5}$ Os indicadores cujo levantamento não foi possível realizar foram excluídos ou adaptados, quando possível.

${ }^{6}$ As pontuações foram redistribuídas de acordo com as adaptações que se fizeram necessárias.
} 
para seus agentes. Por exemplo: um artigo publicado em um periódico tem mais potencial de aumento do prestígio de um pesquisador que um artigo publicado em algum evento científico.

A seguir apresenta-se como foram analisadas cada uma das dimensões da categoria capital científico: Puro: (titulação; experiência profissional; produção intelectual); e Institucional (cargos ocupados $^{7}$; participação em bancas, conselhos, comissões e consultorias). Somando-se a pontuação obtida em cada grupo de indicadores e multiplicando pelo peso correspondente obteve-se uma pontuação correspondente ao volume de capital científico puro e institucional acumulado pelos pesquisadores ao longo de sua trajetória no campo científico da administração universitária. Nesse sentido, tomando por base o trabalho de Teixeira et al. (2012) fez-se uma divisão dos pesquisadores adotando três grupos por intervalos iguais de pontuação com o objetivo de conhecer aqueles situados nos extremos, e aqueles considerados como medianos. Assim, para cada tipo de capital científico, subtraiu-se a maior pontuação obtida pelos pesquisadores pela menor para conhecer a amplitude total das pontuações de cada tipo de capital científico. Dividiu-se a amplitude obtida por três, para definir a amplitude dos intervalos (ou classes). Definidos os intervalos, classificou-se os pesquisadores em três classes, conforme o quadro seguinte:

\begin{tabular}{|c|c|}
\hline Classes & Intervalos \\
\hline A & Pontuação mínima de A - Pontuação máxima de A \\
\hline B & Pontuação mínima de B - Pontuação máxima de B \\
\hline C & Pontuação mínima de C - Pontuação máxima de C \\
\hline
\end{tabular}

Quadro 1 Distribuição dos pesquisadores por volume de capital científico Fonte: Adaptado de Teixeira et al. (2012)

Situando cada pesquisador em uma das três classes, a partir da pontuação obtida por eles em relação ao acúmulo de capital científico, foi possível estabelecer como o campo científico da administração universitária está estruturado.

\subsubsection{Campo científico}

O campo científico da administração universitária no Brasil foi caracterizado a partir do perfil de seus agentes e de sua estrutura, estabelecida via distribuição do capital científico acumulado por seus agentes-pesquisadores. Sendo assim, dividiu-se esta categoria em duas dimensões e oito indicadores: Perfil dos agentes (definidos conforme operacionalização da categoria agentes (seção 3.2.2); Estrutura: (distribuição de capital científico puro e institucional; determinação dos agentes dominantes; possibilidades de conversão do capital

${ }^{7}$ Não foram considerados cargos em substituição. 
científico; e grau de importância das fontes de capital científico). Feita a operacionalização das categorias de análise desse estudo, passa-se a descrever como foi feita a coleta e a análise dos dados de pesquisa.

A coleta de dados deste estudo iniciou-se por meio do levantamento dos sujeitos da pesquisa junto à Plataforma Lattes do CNPq (durante os meses de julho e agosto de 2012) e aos programas de pós-graduação em administração recomendados pela CAPES (durante o mês de junho de 2012). Com esse levantamento, foi possível detectar os agentes do campo científico da administração universitária no Brasil, e a partir do perfil deles caracterizar tal campo, conforme explicado na seção de operacionalização das categorias de análise.

Por meio dos dados constantes nos currículos, especificamente os títulos das publicações dos pesquisadores, foi empreendida uma análise de conteúdo para verificar as possíveis relações dessas publicações com as teorias administrativas. De acordo com Bardin (2004, p. 41) “a análise de conteúdo tem como objetivo a manipulação de mensagens (conteúdo e expressão desse conteúdo), para evidenciar os indicadores que permitam inferir sobre uma outra realidade que não a da mensagem". Mais especificamente, foi utilizada a análise de conteúdo categorial que consiste na classificação dos elementos de um determinado conjunto por diferenciação e reagrupamentos conforme critérios definidos previamente (BARDIN, 2004). Assim, analisaram-se os temas das publicações dos pesquisadores conforme a categoria administração universitária.

Por fim, partindo dos indicadores da operacionalização da categoria capital científico, foram analisados os currículos Lattes dos pesquisadores do campo científico da administração universitária, buscando demonstrar tanto o acúmulo de capital científico puro quanto de capital científico institucional. Em seguida, foi possível determinar como o campo científico está estruturado de acordo com o volume de capital científico acumulado pelos pesquisadores. Para auxiliar na coleta dos dados levantados, foi realizado o registro em planilha Excel e utilizadas as ferramentas de filtro, classificação e tabela dinâmica para auxiliar na análise dos dados.

\section{RESULTADOS}

Nesta seção, são retomados o objetivo central desta pesquisa, as cinco questões de pesquisa dele decorrentes e os respectivos resultados alcançados. 
O problema que deu origem a esta pesquisa foi "Como está constituído o campo científico da administração universitária no Brasil?", o qual culminou no objetivo geral deste trabalho que foi analisar como está constituído este campo científico.

- Questão 1: Que pessoas e/ou instituições podem ser consideradas agentes do campo científico da administração universitária no Brasil?

Para se chegar aos agentes-pesquisadores do campo científico, realizou-se pesquisa na plataforma Lattes do CNPq, buscando por pesquisadores que estivessem ao menos cursando o mestrado, que atuassem na área de administração e que de alguma forma tivessem relação com a administração universitária. Essa relação foi obtida por meio da análise nos currículos Lattes dos pesquisadores: dos resumos dos currículos, do título da dissertação de mestrado, da tese de doutorado ou do trabalho de pós-doutorado, e da área de atuação do pesquisador. Além disso, os pesquisadores deveriam ter atualizado o currículo no ano de 2012. Chegou-se a um total de 233 pesquisadores do campo científico da administração universitária no Brasil.

Quanto aos agentes-grupos de pesquisa do campo científico da administração universitária no Brasil, também foram identificados por meio de pesquisa na Plataforma Lattes, por meio de busca no Diretório de Grupos de Pesquisa da mesma, buscando por grupos relacionados à administração universitária que atuassem na área de administração. Chegou-se a um total de 17 grupos de pesquisa em administração universitária.

Os cursos de pós-graduação stricto sensu e as instituições de ensino superior em que se localizam foram identificados como agentes do campo científico, por meio da análise da área de concentração, das linhas de pesquisa e da estrutura curricular de cada curso de mestrado e doutorado da área de administração no Brasil, de modo a verificar sua relação com a administração universitária. Foram identificados 18 cursos de pós-graduação stricto sensu e 13 instituições de ensino superior relacionados a eles.

Além desses, foram considerados como agentes, ainda que indiretamente relacionados ao campo científico: a ANPAD, por se tratar de um agente importante do campo da administração ao qual a administração universitária faz parte; e a CAPES, por ser um órgão regulador e de fomento das atividades da pós-graduação no Brasil. Embora estes não tenham sido o foco de análise, foram utilizadas como base para a operacionalização de categorias de análise da pesquisa, justamente por sua influência no campo.

A partir da identificação de agentes do campo científico da administração universitária no Brasil, foi possível caracterizá-los, e responder a segunda questão de pesquisa.

\section{- Questão 2: Como esses agentes podem ser caracterizados?}


Os agentes-pesquisadores foram caracterizados por meio de seu perfil demográfico e de seu perfil acadêmico. Entre os agentes-pesquisadores do campo, prevalece os do sexo masculino (53\%). Quanto aos locais de atuação, a maior parte deles se concentra na Região Sul (50\%), no estado de Santa Catarina (30\%) e na cidade de Florianópolis (17\%). Destaca-se, ainda a presença de pesquisadores do campo em todos as regiões brasileiras; 21 estados, além do Distrito Federal (Acre, Amapá, Mato Grosso, Maranhão e Sergipe não contém pesquisadores do campo); e 83 municípios brasileiros. Há um pesquisador atuando em Londres, Inglaterra. Os pesquisadores do campo da administração universitária no Brasil atuam em 108 instituições de educação superior, incluindo uma inglesa. Os temas mais presentes entre as publicações na área de administração universitária feita pelos pesquisadores estão relacionados aos classificados como específicos, ou seja, aqueles que podem estar ligados a outras áreas que não a administração.

Os agentes-grupos de pesquisa também foram caracterizados conforme seu perfil demográfico e acadêmico. Quanto ao local de funcionamento, a região Sudeste é a que mais concentra grupos de pesquisa no campo científico da administração universitária no Brasil (8 de 17). A UFSC e a UFPE possuem dois grupos de pesquisa pertencentes ao campo cada, sendo as únicas instituições com mais de um grupo. Os agentes-grupos de pesquisa do campo científico da administração universitária no Brasil têm sua atuação mais voltada para os temas específicos de administração universitária, pois foram os que com maior frequência apareceram nas linhas de pesquisa e repercussões dos trabalhos dos grupos.

Por fim, os agentes-cursos de pós-graduação/instituições de ensino superior foram caracterizados quanto ao seus perfis demográfico e acadêmico. Quanto aos locais de atuação, Florianópolis é a cidade que mais concentra cursos de pós-graduação stricto sensu relacionados à administração universitária (4 de 18); Santa Catarina é o estado que mais contém esses cursos (5 de 18); e quanto à região, a Sudeste é a que mais concentra esses cursos (6 de 18). Em relação às instituições de educação superior onde estão localizados esses cursos, destaca-se a UFSC, com três cursos, sendo um exclusivamente na área de administração universitária. Quanto aos cursos, ressalta-se que a maioria (74\%) tem os menores conceitos ( 3 e 4 ) dentre os estabelecidos pela CAPES para funcionamento dos cursos de pós-graduação (que vai de 3 a 7). Apenas três cursos têm conceito intermediário (5). Quanto aos motivos que levaram à classificação dos cursos como pertencentes ou relacionados ao campo científico da administração universitária verifiquei que a maioria está relacionada a existência de disciplinas (em 11 dos 18 cursos esse foi o motivo) ligadas as suas 
temáticas. Outros seis cursos têm linhas de pesquisa relacionadas aos temas de administração universitária. E um curso está totalmente vinculado ao campo (o mestrado profissional em administração universitária da UFSC). Quanto aos temas a que essas linhas de pesquisa e disciplinas que justificaram relacionar os cursos ao campo, destacam-se os vinculados aos temas específicos de administração universitária, sendo o tema de educação a distância o mais frequente.

A partir da caracterização desses agentes, pôde-se perceber que a Universidade Federal de Santa Catarina é um agente de destaque no campo científico da administração universitária no Brasil. É uma das instituições que mais estão relacionadas aos agentespesquisadores do campo científico da administração universitária no país: concentra o maior percentual de pesquisadores atuando profissionalmente (12\%); foi nela que $16 \%$ dos pesquisadores se formaram na graduação; $35 \%$ concluiu o mestrado; $41 \%$ concluiu o doutorado; sedia o segundo periódico (Revista de Ciência da Administração - CAD/UFSC) com o maior volume de publicações dentre os pesquisadores do campo (3\%); é uma das organizadoras do evento científico (Colóquio Internacional sobre Gestão Universitária nas Américas) que concentra o maior volume de publicações (25\%) em administração universitária no campo; que se sedia o terceiro periódico (Revista Gestão Universitária na América Latina - GUAL) em concentração de membros de corpo editorial (cinco membros, ou 2\% do total). Além disso, foi pioneira no Brasil na oferta de curso de mestrado com área de concentração em administração universitária (CPGA/UFSC) na área de administração; bem como sedia o único curso de mestrado em administração universitária na área de administração no Brasil (PPGAU/UFSC). A UFSC acaba se tornando um agente de destaque para o campo científico da administração universitária no Brasil, como formadora e fomentadora de pesquisa na área por meio de publicações e eventos na área.

Caracterizados os agentes do campo científico da administração universitária no Brasil, foi possível analisar os temas trabalhados neste campo e responder à questão seguinte.

\section{- Questão 3: Quais as possíveis influências das teorias administrativas nos temas} de interesse dos agentes?

Por meio da análise dos temas das publicações dos pesquisadores, das linhas de pesquisa e da atuação dos grupos de pesquisa, bem como das áreas de concentração, das linhas de pesquisa e da estrutura curricular dos cursos de mestrado e doutorado relacionados à administração universitária foi possível constatar indícios da influência das teorias administrativas nos temas de interesse dos agentes. 
Verificou-se que entre os temas mais presentes entre nas publicações dos agentespesquisadores estão aqueles ligados aos específicos, de acordo com a categorização feita no capítulo de metodologia. Assim, em todos os tipos de publicações (dissertações e teses, projetos de pesquisa coordenados e integrados pelos pesquisadores, periódicos, eventos, livros e capítulos de livros) prevaleceram os temas específicos da administração universitária, com destaque para os temas ensino, pesquisa e extensão, avaliação da educação superior e educação a distância, temas que mais frequentemente apareceram entre os três mais publicados, respectivamente. Quanto aos temas de administração universitária ligados à área de administração, destacam-se os relacionados às áreas funcionais da administração que somente em relação aos projetos de pesquisa não prevaleceram sobre as demais temas (teorias gerenciais e teorias das organizações). Dentre os mais frequentes entre as áreas funcionais destacam-se nesta ordem: administração estratégica, administração de pessoas e administração da informação. Entre as teorias gerenciais, segunda dimensão com a maior frequência de temas, destacam-se: planejamento, direção e controle, respectivamente. Entre os temas relacionados às teorias das organizações prevaleceram: conhecimento, aprendizagem e inovação, redes e relacionamentos intra e interorganizacionais e trabalho, organização, Estado e sociedade, nesta ordem.

Os agentes-grupos de pesquisa do campo científico da administração universitária no Brasil têm sua atuação mais voltada para os temas específicos de administração universitária, pois foram os que com maior frequência apareceram nas linhas de pesquisa e repercussões dos trabalhos dos grupos, com destaque para ensino, pesquisa e extensão, cooperação universidade-empresa e avaliação da educação superior. Entre os temas relacionados às teorias administrativas destacam-se os voltados às áreas funcionais da administração, principalmente administração estratégica, administração financeira e administração de pessoas. Destaca-se também o tema de planejamento entre as teorias gerenciais.

Entre os temas prevalecentes nas áreas de concentração, linhas de pesquisa e estrutura curricular dos cursos de mestrado e doutorado relacionados à administração universitária destacam-se os vinculados aos temas específicos de administração universitária, sendo o tema de educação a distância o mais frequente, seguido de avaliação institucional. Entre os relacionados às teorias administrativas destacam-se os relacionados às áreas funcionais, principalmente administração da informação e administração estratégica. Cabe destacar o curso de mestrado profissional em administração profissional da UFSC - PPGAU/UFSC como um agente de destaque entre os cursos relacionados ao campo, pois é o único totalmente 
voltado para a temática. Foi possível constatar a presença equilibrada de temas específicos da administração universitária e de relacionados às teorias administrativas. Quanto aos primeiros foram constatados: gestão universitária; políticas de educação superior; universidade e sociedade; cooperação universidade-empresa; avaliação institucional; estrutura e funcionamento da educação superior; educação a distância; ensino, pesquisa e extensão; e universidade e desenvolvimento regional. Quanto aos temas relacionados às teorias administrativas observou-se: planejamento e direção (teorias gerenciais); administração financeira, administração da informação, administração estratégica, administração de marketing e administração de recursos humanos (áreas funcionais da administração); e conhecimento, aprendizagem e inovação e história e memória em organizações (teorias das organizações).

Conclui-se que os temas do campo científico da administração universitária sofrem influência das teorias administrativas, com destaque para as áreas funcionais da administração, principalmente administração estratégica, administração da informação e administração de pessoas. Porém, prevalecem os temas considerados como específicos da área que não necessariamente estão relacionados com a administração. Entre tais temas destacamse: ensino, pesquisa e extensão, educação a distância e a avaliação da educação superior.

Verificadas as influências das teorias administrativas nos temas de interesse dos agentes do campo científico da administração universitária no Brasil, parte-se para a última questão que esta pesquisa buscou responder.

- Questão 4: De que forma está estruturado o campo científico da administração universitária no Brasil, considerando o acúmulo de capital científico de seus agentes?

O campo científico da administração universitária está estruturado de forma desigual, seja analisando a distribuição do capital científico puro entre os agentes-pesquisadores, seja analisando a distribuição do capital científico institucional. Isto ocorre, pois uma minoria dos pesquisadores concentra um volume de capital científico igual ou próximo ao que acumula a maioria dos pesquisadores do capital científico. Tais dados corroboram com a ideia de Bourdieu (1983, p. 136) de que "o campo científico é sempre o lugar de uma luta, mais ou menos desigual, entre agentes desigualmente dotados de capital específico”. Decorrente dessa constatação de desigualdade no campo verificou-se que pertencer ao grupo dos "mais prestigiados", ou dos que possuem maior volume de capital científico puro (60\% acumulam $26 \%$ de capital) é mais difícil que pertencer ao grupo dos "mais poderosos" institucionalmente, ou que possuem o maior volume de capital científico institucional (52\% 
acumulam 21\% de capital). Assim, há uma desigualdade relativamente maior considerando-se a distribuição do capital científico puro no campo. Outra constatação observada foi a de que a maior parte dos pesquisadores do campo científico da administração universitária no Brasil possui relativamente ao volume de capital científico de seus pares, um baixo acúmulo de capital científico, tanto puro (60\% dos pesquisadores pertencem à classe C) quanto institucional (52\% pertencem a classe C). Isso implica que há uma provável barreira à entrada imposta aos agentes que desejam obter prestígio no campo, que é dada pelo "capital científico coletivamente acumulado" (BOURDIEU, 2004, p. 35) pelos agentes dominantes deste campo, conforme se retomará mais adiante.

Constatou-se também que apenas uma pequena parte dos pesquisadores (4\%) conseguem ocupar posições de destaque no campo tanto em função de seu prestígio junto aos pares quanto em decorrência do poder temporal que exercem. Tal fato corrobora com o que diz Bourdieu (2004) sobre a dificuldade de acumular as duas espécies da capital científico. Há, portanto, nove casos em que os agentes-pesquisadores do campo científico da administração universitária no Brasil são ao mesmo tempo socialmente e cientificamente dominantes (BOURDIEU, 2004) na medida em que conseguem ocupar as mais altas posições hierárquicas tanto na estrutura de distribuição do capital científico puro quanto na do capital científico institucional. Para Bourdieu (2004), o mais comum é que ou o agente seja cientificamente ou socialmente dominante. No campo científico da administração universitária isso ocorre em 9\% dos casos, sendo que apenas 21 dos 233 pesquisadores se encontram nessa situação. Sendo que destes, há cinco que ocupam as posições extremas, ou seja, um forte peso político e frágil crédito científico, os chamados "administradores científicos" (caso de quatro pesquisadores) de um lado e de outro aqueles que foram denominados neste trabalho de "pesquisadores científicos" (caso de 1 pesquisador), com forte crédito científico e frágil peso político. Isso significa, conforme Bourdieu (2004), que quatro pesquisadores tem um alto capital científico decorrente não de suas contribuições para o avanço da ciência, mas principalmente em função da ocupação de espaços de poder no campo.

É possível observar também que $59 \%$ dos pesquisadores do campo científico da administração universitária no Brasil ocupam as mesmas classes de distribuição de capital científico puro e institucional. Destes, $4 \%$, como já foi mostrado pertence ao mesmo tempo à classe $\mathrm{A}, 16 \%$ à classe $\mathrm{B}$ e $39 \%$ à classe $\mathrm{C}$ do campo científico da administração universitária no Brasil. Esses dados vão ao encontro do que diz Bourdieu (2004) sobre a ambiguidade 
estrutural dos campos científicos ou de que a ciência é relativamente autônoma. Porém, percebe-se que a medida que se aumenta a classe em que estão situados os agentes, menor é a chance de acúmulo dos dois tipos de capital científico, dada a dificuldade de isso ocorrer como já explicado.

Outro aspecto de destaque diz respeito aos agentes-pesquisadores dominantes que são aqueles que podem ditar o que é importante ser e ter para atuar neste campo. Identificou-se como agentes dominantes um total de 30 agentes-pesquisadores, que foram os que mais acumularam capital científico puro ou institucional no campo. Em primeiro lugar, traçou-se um breve perfil desses agentes, onde foi constatado que a maioria é do sexo masculino: 20 dos 30 pesquisadores, ou seja, $67 \%$. Tal resultado vai ao encontro de estudos como os do próprio Bourdieu (1999) em que a mulher tem dificuldade para alcançar determinados espaços de poder. Quanto às instituições em que atuam os agentes dominantes destacam-se a UFSC e a UFRN (com 4 pesquisadores cada); FURB (com 3 pesquisadores); e UNOESC, UNINOVE, UEM e UFES (com 2 pesquisadores cada). Outras 11 instituições apareceram como locais de atuação dos demais agentes dominantes. Entre os locais de concentração de agentes dominantes do campo científico da administração universitária no Brasil, verifica-se, por meio da localização das instituições, que a maioria se encontra na cidade de Florianópolis (5 no total); no estado de Santa Catarina (10 no total); e na região Sul (15 no total) do país. Tais locais convergem com os mesmos que concentram o maior número de agentes-pesquisadores em geral, o que indica uma tendência de concentração dos pesquisadores do campo junto aos agentes dominantes desse campo.

Outro aspecto levantado junto aos agentes dominantes diz respeito ao seu capital científico. Assim, verificou-se quais fontes de capital científico têm mais importância relativa para obtenção de poder científico no campo científico da administração universitária no Brasil.

Quanto aos indicadores de capital científico puro, foram considerados como muito importantes para a obtenção de prestígio no campo: a titulação de doutor (97\%) e a formação pós-doutoral (50\% possuem); a coordenação de projetos de pesquisa; as publicações em periódicos, independente da qualificação; a publicação de capítulos de livros; a publicação de artigos em anais de eventos científicos; a coordenação de projetos de pesquisa com fomento. Foram considerados como pouco importantes: a orientação de dissertações e teses; a atuação como integrante de projeto de pesquisa; a obtenção de bolsas durante o mestrado, doutorado 
ou pós-doutorado; as publicações em periódicos Qualis A1 ou A2 em Administração; e a publicação de livros.

Quanto aos indicadores de capital institucional, foram considerados como fontes muito importantes para a obtenção de poder temporal: a ocupação de cargos de direção e administração (coordenação, direção, chefia); a participação em conselhos, comissões e consultorias; a participação em bancas de dissertações e teses; a atuação como revisor de periódico.

Foram considerados pouco importantes para a obtenção de capital científico institucional, os seguintes indicadores: a ocupação de cargos de direção e administração ocupados (Reitoria, Pró-Reitoria); a participação em bancas de concursos públicos; a participação em avaliação de cursos; a atuação como membro de corpo editorial.

Vale destacar que o grau de importância dos indicadores de capital científico servem de parâmetro para os demais agentes do campo científico da administração universitária no Brasil. Aquele que quer se destacar neste campo, deve considerar quais fontes de obtenção de prestígio e de poder temporal os agentes consideram importantes para se "jogar o jogo" (BOURDIEU, 1983). Não se deve deixar de comentar o fato de que as "regras do jogo" (BOURDIEU, 1983) servem de parâmetro tanto para os novatos que querem se opor aos agentes dominantes quanto aos que querem sucedê-los, pois mesmo aqueles "só poderão vencer os dominantes em seu próprio jogo" (BOURDIEU, 1983, p. 138).

\section{CONSIDERAÇÕES FINAIS}

Este é um trabalho inicial que deve ser aprimorado, criticado, refeito, ou mesmo negado, mas que pretende servir para que seus agentes reflitam sobre o próprio campo em que atuam. Há muito que se fazer, se é que esse é o desejo de seus pesquisadores. Assim, a partir deste trabalho buscou-se contribuir para que se iniciem discussões em torno do espaço da administração universitária enquanto campo científico. Para tanto, são indicadas algumas sugestões para trabalhos futuros, considerando as respostas às questões desta pesquisa. Acredita-se que tais questões possam ajudar a compreender ainda melhor como o campo científico da administração universitária no Brasil se constitui, fortalecendo as pesquisas na área:

- Historicamente como a administração universitária se constituiu como um campo científico no Brasil? Que fatores contribuíram para isso? 
- Que outros campos poderiam servir de ponto de partida para se analisar o campo científico da administração universitária no Brasil?

- Como a estrutura do campo científico da administração universitária se transforma ao longo do tempo? Os agentes dominantes permaneceram sempre os mesmos? A desigualdade e a distribuição do capital científico entre seus agentes foi semelhante ao longo do tempo?

- Que correntes do pensamento científico fundamentam epistemologicamente a produção científica do campo científico da administração universitária?

- O campo científico da administração universitária é um campo que extrapola as fronteiras nacionais? Como este campo se constitui em outros países?

Por fim, cabe reconhecer a limitação da abordagem empregada. A teoria dos campos de Bourdieu, neste caso, o científico, obviamente não explica tudo. Há uma série de lacunas que ainda podem e devem ser exploradas para entender como o campo científico da administração universitária está constituído, como está estruturado, quem o constitui, entre outros elementos. Provavelmente há outros tipos de agentes e de relações. A abordagem de Bourdieu apresentou-se como viável para desvendar inicialmente o campo, mas lacunas ainda podem ser percebidas e há infinitas possibilidades para tentar preenche-las. O trabalho continua.

\section{REFERÊNCIAS}

ANPAD - ASSOCIAÇÃO NACIONAL DE PÓS-GRADUAÇÃO E PESQUISA EM ADMINISTRAÇÃO. Temas de interesse. 2011b. Disponível em:

$<$ http://www.anpad.org.br/evento.php?acao=subsecao\&cod_edicao_subsecao=676\&cod_even to_edicao=58> Acesso em: jul.2011.

ÁVILA, Patrícia. A distribuição do capital científico: diversidade interna e permeabilidade externa do campo científico. Sociologia - Problemas e Práticas. no 25. 1997. p. 9-49.

BARDIN, L. Análise de conteúdo. Lisboa, Portugal: Edição 70, 2004.

BOUDON et al. Dicionário de Sociologia. Dom Quixote: Lisboa, 1990, http://www.ebah.com.br/content/ABAAAAW-AAB/dicionario-sociologia

BOURDIEU, Pierre. A dominação masculina. Rio de Janeiro: Bertrand Brasil, 1999.

. As Regras da Arte: gênese e estrutura do campo literário. 2 ed. São Paulo:

Companhia das Letras, 2005.

O campo científico. In: ORTIZ, R. Sociologia. São Paulo: Ática, 1983. 
Os usos sociais da ciência. Por uma sociologia clínica do campo científico. São Paulo: UNESP, 2004.

Homo academicus. Florianópolis: Ed. da UFSC, 2011.

HAGSTROM, W. O. O controle social dos cientistas. In: DEUS, Jorge Dias de (org.). A Crítica da Ciência: sociologia e ideologia da ciência. 2.ed. Rio de Janeiro: Zahar Editores, 1979.

LAHIRE, Bernard. Homem Plural: os determinantes da ação. Petrópolis: Vozes, 2002.

MERTON, R.K. Os imperativos institucionais da ciência. In: DEUS, Jorge Dias de (org.). A crítica da ciência: sociologia e ideologia da ciência. 2.ed. Rio de Janeiro: Zahar, 1979.

RUBEN, Guilhermo; SERVA, Maurício; CASTRO, Marco Luiz de. Resíduos e complementaridade: da relação entre a teoria de administração e a antropologia. Anais do XIX ENANPAD. João Pessoa: ANPAD, 1995.

SHINN, Terry; RAGOUET, Pascal. Controvérsias sobre a ciência: por uma sociologia transversalista da atividade científica. São Paulo: Editora 34, 2008.

STENGERS, Isabelle. Quem tem medo da ciência? : ciências e poderes. São Paulo: Siciliano, 1990.

TEIXEIRA, Juliana Cristina. et al. Dinâmica de distribuição de fontes de capitais científicos entre docentes / pesquisadores de um programa de pós-graduação stricto-sensu de uma universidade pública. Avaliação. Campinas; Sorocaba, SP, v.17, n.1, p. 179-206, mar.2012.

UFRGS - UNIVERSIDADE FEDERAL DO RIO GRANDE DO SUL. Concurso de público de títulos e provas para provimento de cargo na classe de professor adjunto. Disponível em : http://www.ufrgs.br/progesp/progesp-1/concursos-publicos/magisteriosuperior/concuros/2011/edital-17-2011/arquivos/orientacoes/Ed\%20172011\%20ADM\%20Administracao\%20Financeira.pdf Acesso em dez.2011.

VIEIRA, Marcelo Milano Falcão. Por uma boa pesquisa (qualitativa) em Administração. In: VIEIRA, M.M.F.; ZOUAIN,D.M. (Org). Pesquisa qualitativa em administração. Rio de Janeiro: Editora FGV, 2004. 